www.jmscr.igmpublication.org

Impact Factor 5.84

Index Copernicus Value: 71.58

ISSN (e)-2347-176x ISSN (p) 2455-0450

crossref DOI: _https://dx.doi.org/10.18535/jmscr/v5i10.140

Journal Of Medical Science And Clinical Research

IGM Publication

An Official Publication of IGM Publication

\title{
Classification and Distribution of Gujarati and Non Gujarati Girls According to Obesity Epidemiology: A Prevalence Study
}

\author{
Authors \\ Nita Sahi ${ }^{1}$, Nidhi Ranawat ${ }^{2}$, Shubham Jain ${ }^{3}$ \\ ${ }^{1}$ Assistant Professor, Department of Biochemistry PMCH Udaipur \\ ${ }^{2,3}$ PG Student, Department of Biochemistry PMCH Udaipur
}

\begin{abstract}
The WHO has drawn attention to fact that obesity is our modern non communicable "epidemic" that is, disease that affects population not an unavoidable attribute of aging ${ }^{[2]}$. Until recently, females were thought to be protective gender, due to their hormone, estrogen but recent data collected from American Heart Association reveals that since two decades every year globally more females die of this cause than all other causes of death combined together ${ }^{[9]}$. For this reason, we decided to study the prevalence of overweight and obesity in the girls of two communities that is Gujarati's and Non Gujarati's and segregated them in various groups to match the various parameters against them. The 1001 girls residing in different hostels from different colleges were selected for the study. Two groups were made and the total girls were categorized into Gujarati and Non Gujarati groups respectively. They were further classified according to categories like age, inhabitance, socioeconomic status, diet, weight, height, body mass index, Majority of our subjects were more than 20 years of age (52\%). Most of them (76\%) belonged to urban areas and $45 \%$ had middle socio economic status. Mainly the girls were strictly vegetarians (72\%). Sixty percent total girls had a weight range of 53-65kg. Only $20 \%$ had height less than $1.52 \mathrm{~m}$. Forty percent were in overweight category according to body mass index with BMI range of 25$29.9 \mathrm{Kg} / \mathrm{m} 2$.

Keywords: MDA, WHR, BMI, Fibre, Obesi.
\end{abstract}

\section{Introduction}

The dramatic increase in the prevalence of obesity over the past few decades strongly suggest that preventive strategies will become more important as time goes on. ${ }^{[6]}$ Public health approaches that emphasize education have almost been uniformly unsuccessful at preventing weight gain or producing weight loss. Public health strategies that virtually impose behavior change along with healthy food are more successful in this regard. ${ }^{[3]}$ The average weight, body mass index, waist circumference, hip circumference, waist hip ratio, body fat percent total body fat, lean body mass and skin fold thickness in girls of age less than 20 were low as compared to the higher age groups $(59.58 \pm 6.84 \mathrm{~kg}$ v/s $60.06 \pm 6.85 \mathrm{~kg} ; 24.03 \pm 3.09 \mathrm{~kg} /$ $\mathrm{m} 2 \mathrm{v} / \mathrm{s} \quad 24.39 \pm 3.43 \mathrm{~kg} / \mathrm{m} 2 ; 29.18 \pm 3.23 \mathrm{~cm} \mathrm{v} / \mathrm{s}$ $29.8 \pm 3.54 \mathrm{~cm} ; \quad 35.82 \pm 1.71$ inches $\quad \mathrm{v} / \mathrm{s} \quad 35.91 \pm$ linches.78; $0.82 \pm 0.08 \mathrm{v} / \mathrm{s} \quad 0.83 \pm 0.09 ; \quad 25.18 \pm$ $7.65 \% \mathrm{v} / \mathrm{s} 26.75 \pm 8.16 \% ; 17.29 \pm 4.5 \mathrm{~kg}$ v/s $17.81 \pm$ $4.76 \mathrm{~kg} ; 42.25 \pm 2.73 \mathrm{~kg}$ v/s $42.29 \pm 2.89 \mathrm{~kg} ; 55.63 \pm$ $8.72 \mathrm{~mm} \mathrm{v} / \mathrm{s} 56.41 \pm 7.98 \mathrm{~mm})$. Waist circumference 
in lower class was $29 \pm 3.17 \mathrm{~cm}$ as compared to waist circumference of $30 \pm 3.50 \mathrm{~cm}$ in the middle class. Body fat percent was also higher for the middle category $(26 \pm 8.12 \%)$ as compared to that in the lower class $(25 \pm 7.24 \%)$. Total body fat was higher for middle and upper class $(18 \pm 4.76 \mathrm{~kg}$, $18 \pm 4.49 \mathrm{~kg}$ ) in comparison to that in lower class $(17 \pm 4.60 \mathrm{~kg})$.

\section{Material and Method}

The present study encompasses classification and distribution of girls from 2 different communities according to obesity epidemiology aged between 18 to 30 years. The girls were residing in hostels of Pacific Dental College, Udaipur.

\section{Selection of Girls for the Study}

This study has been conducted on 1001 girls who were residing in different institutional hostels like Geetanjali Medical College, Dental Colleges, Engineering Colleges, Pharmacy Colleges and others. Actually these girls had come from different districts of Gujarat, Rajasthan mainly and also from other States like Maharashtra, Uttar Pradesh, Madhya Pradesh etc. for higher studies, so they were selected for this study. Girls were randomly selected irrespective of their caste and creed. Interview schedule was developed to collect the general information regarding age, dietary habits, socioeconomic status, suffering from any illness, or taking any treatment, caste, religion etc. The subjects with any clinical or biochemical evidence of liver, kidney or endocrine disease and those on treatment that effect the lipid metabolism were excluded from the study. The categorization of obese subjects were made on the basis of body mass index (BMI) or waist hip ratio (WHR) or standard chart of desirable weight in relation to height, published by Metropolitan Life Insurance Company (Bray, 1978) $[\mathrm{REF}]$ as well as on the basis of skin fold thickness (Darnin and Womersley, 1974) [REF]. Normal subjects of identical age group with that of respective obese group acted as control.
Measurement of different Anthropometric parameters:

i. Age: The age of the Gujarati and non Gujarati girls were recorded from their personal biodata

ii. Height: Height was recorded using a measuring scale, with the individual standing straight without shoes next to the wall, with the heels, buttocks, shoulders and occipital touching the wall. The head was kept erect. The measuring scale was fixed on the wall. Height was measured in centimeters to the nearest of $0.1 \mathrm{~cm}$ to the nearest $0.1 \mathrm{~cm}$.

iii. Weight: Weight was recorded by weighing machine calibrated daily at the beginning of each working day. The individual was requested to wear light dress and the weight was recorded with the individual barefooted by taking two successive readings to the nearest $100 \mathrm{gm}$, the mean of which was recorded.

iv. BMI: The most widely used clinical tool for measurement of obesity is the Body Mass Index (BMI) i.e. wt. in $\mathrm{Kg} / \mathrm{m} 2$ height

BMI was accurately calculated using SI units. BMI was categorized as follows as per reported [4].

\begin{tabular}{|c|c|}
\hline Category & BMI range- $\mathbf{k g} / \mathbf{m}^{\mathbf{2}}$ \\
\hline Starvation & Less than 16 \\
\hline Underweight & From 16.5 to 18.5 \\
\hline Normal & From 18.5 to 24.9 \\
\hline Overweight & From 25 to 29.9 \\
\hline Obese & From 30 to 35 \\
\hline
\end{tabular}

Recently the Ministry's Consensus for the prevention and management of obesity and metabolic syndrome for the country has declared that the country's new diagnostic cut off for the body mass index is $23 \mathrm{~kg} / \mathrm{m} 2$ as opposed to $25 \mathrm{~kg} / \mathrm{m} 2$ globally [Health Ministry, Diabetes Foundation of India, All India Institute of Medical 
Sciences, Indian Council of Medical Research, The National Institute of Nutrition, 11/26/2008]. According to them, a person above body mass index of $23 \mathrm{~kg} / \mathrm{m} 2$ will now be considered as overweight and below that as one with normal BMI - unlike the cut off limit of $25 \mathrm{~kg} / \mathrm{m} 2$ earlier. Those with BMI of $25 \mathrm{~kg} / \mathrm{m} 2$ will be clinically termed obese as opposed to $30 \mathrm{~kg} / \mathrm{m} 2$ at the international level, and those with BMI of $32.5 \mathrm{~kg} / \mathrm{m} 2$ will require bariatric surgery to estimate excess flab.

\section{Statistical Analysis}

Data were analyzed statistically by using student $\mathrm{t}$ test with the help of SPSS software version 19.

\section{Results}

Prevalence of Total, Gujarati and Non-Gujarati girls according to Age:

Our analysis uncovers that weight increases with age. More percentage of overweight and obese girls was above 20 year age group. The average weight, body mass index, waist circumference, hip circumference, waist hip ratio, body fat percent total body fat, lean body mass and skin fold thickness in girls of age less than 20 were low as compared to the higher age groups $(59.58 \pm 6.84 \mathrm{~kg}$ $\mathrm{v} / \mathrm{s} \quad 60.06 \pm \quad 6.85 \mathrm{~kg} ; \quad 24.03 \pm 3.09 \mathrm{~kg} / \mathrm{m} 2 \quad \mathrm{v} / \mathrm{s}$ $24.39 \pm 3.43 \mathrm{~kg} / \mathrm{m} 2 ; \quad 29.18 \pm 3.23 \mathrm{~cm} \quad \mathrm{v} / \mathrm{s} \quad 29.8 \pm$ $3.54 \mathrm{~cm} ; 35.82 \pm 1.71$ inches $\mathrm{v} / \mathrm{s} 35.91 \pm 1$ inches.78; $0.82 \pm 0.08 \quad \mathrm{v} / \mathrm{s} \quad 0.83 \pm 0.09 ; \quad 25.18 \pm 7.65 \% \quad \mathrm{v} / \mathrm{s}$ $26.75 \pm 8.16 \% ; \quad 17.29 \pm 4.5 \mathrm{~kg} \quad \mathrm{v} / \mathrm{s} \quad 17.81 \pm 4.76 \mathrm{~kg}$; $42.25 \pm 2.73 \mathrm{~kg}$ v/s $42.29 \pm 2.89 \mathrm{~kg} ; 55.63 \pm 8.72 \mathrm{~mm}$ v/s $56.41 \pm 7.98 \mathrm{~mm})$.

Table: 1 Distribution of Girls according to age

\begin{tabular}{|c|c|c|c|c|c|c|}
\hline \multirow{2}{*}{ Age(years) } & \multicolumn{2}{|c|}{ Gujrati Girls } & \multicolumn{2}{c|}{ Non -Gujrati Girls } & \multicolumn{2}{c|}{ Total Girls } \\
\cline { 2 - 7 } & $(\mathbf{n})$ & $(\boldsymbol{\%})$ & $(\mathbf{n})$ & $(\%)$ & $(\mathbf{\%})$ & $(\%)$ \\
\hline$>20$ years & 192 & $36 \%$ & 328 & $69 \%$ & 520 & $52 \%$ \\
\hline < 20 years & 334 & $64 \%$ & 147 & $31 \%$ & 481 & $48 \%$ \\
\hline Total Girls & 526 & $100 \%$ & 475 & $100 \%$ & 1001 & $100 \%$ \\
\hline
\end{tabular}

Table No.2 Distribution of Girls according to Inhabitance

\begin{tabular}{|c|c|c|c|c|c|c|}
\hline \multirow{2}{*}{ Inhabitance } & \multicolumn{2}{|c|}{ Gujrati Girls } & \multicolumn{2}{|c|}{ Non -Gujrati Girls } & \multicolumn{2}{|c|}{ Total Girls } \\
\hline & (n) & $(\%)$ & (n) & $(\%)$ & (n) & $(\%)$ \\
\hline Rural Inhabitance & 69 & $13 \%$ & 173 & $36 \%$ & 242 & $24 \%$ \\
\hline Urban Inhabitance & 457 & $87 \%$ & 302 & $64 \%$ & 759 & $76 \%$ \\
\hline Total Girls & 526 & $100 \%$ & 475 & $100 \%$ & 1001 & $100 \%$ \\
\hline
\end{tabular}

Table No.3 Distribution of Girls according to Socio-economic status

\begin{tabular}{|l|c|c|c|c|c|c|}
\hline \multirow{2}{*}{ Socio economic status } & \multicolumn{2}{|c|}{ Gujrati girls } & \multicolumn{2}{c|}{ Non -Gujrati girls } & \multicolumn{2}{c|}{ Total girls } \\
\cline { 2 - 7 } & $(\mathbf{n})$ & $\mathbf{( \% )}$ & $\mathbf{( n )}$ & $\mathbf{( \% )}$ & $(\mathbf{n})$ & $(\boldsymbol{\%})$ \\
\hline Lower & 64 & $12 \%$ & 130 & $27 \%$ & 194 & $19 \%$ \\
\hline Middle & 183 & $35 \%$ & 264 & $56 \%$ & 447 & $45 \%$ \\
\hline Upper & 279 & $53 \%$ & 81 & $17 \%$ & 360 & $36 \%$ \\
\hline Total Girls & 526 & $100 \%$ & 475 & $100 \%$ & 1001 & $100 \%$ \\
\hline
\end{tabular}


Table No.4 Distribution of girls according to Dietary Habits

\begin{tabular}{|l|c|c|c|c|c|c|}
\hline \multirow{2}{*}{ Dietary Habits } & \multicolumn{2}{|c|}{ Gujrati girls } & \multicolumn{2}{c|}{ Non -Gujrati girls } & \multicolumn{2}{c|}{ Total girls } \\
\cline { 2 - 7 } & $\mathbf{( n )}$ & $\mathbf{( \% )}$ & $\mathbf{( n )}$ & $\mathbf{( \% )}$ & $(\mathbf{n})$ & $(\%)$ \\
\hline Vegetarian & 404 & $77 \%$ & 317 & $67 \%$ & 721 & $72 \%$ \\
\hline Non- Vegetarian & 122 & $23 \%$ & 158 & $33 \%$ & 280 & $28 \%$ \\
\hline Total Girls & 526 & $100 \%$ & 475 & $100 \%$ & 1001 & $100 \%$ \\
\hline
\end{tabular}

Table No.5 Distribution of Girls according to the Weight range

\begin{tabular}{|l|c|c|c|c|c|c|}
\hline \multirow{2}{*}{ Weight Range (kg) } & \multicolumn{2}{|c|}{ Gujrati Girls } & \multicolumn{2}{c|}{ Non -Gujrati } & \multicolumn{2}{c|}{ Gotal Girls } \\
\cline { 2 - 7 } & $(\mathbf{n})$ & $\boldsymbol{\%}$ & (n) & $\mathbf{\%}$ & (n) & \% \\
\hline $40-52$ & 77 & $15 \%$ & 70 & $15 \%$ & 147 & $15 \%$ \\
\hline $53-65$ & 335 & $64 \%$ & 268 & $56 \%$ & 603 & $60 \%$ \\
\hline $66-80$ & 114 & $21 \%$ & 137 & $29 \%$ & 251 & $25 \%$ \\
\hline Total Girls & 526 & $100 \%$ & 475 & $100 \%$ & 1001 & $100 \%$ \\
\hline
\end{tabular}

Table No.6 Distribution of Girls according to the Height

\begin{tabular}{|l|c|c|c|c|c|c|}
\hline \multirow{2}{*}{ Height (meters) } & \multicolumn{2}{|c|}{ Gujrati Girls } & \multicolumn{2}{c|}{ Non -Gujrati Girls } & \multicolumn{2}{c|}{ Total Girls } \\
\cline { 2 - 7 } & $(\mathbf{n})$ & $\boldsymbol{\%}$ & (n) & \% & (n) & \% \\
\hline$<1.52$ & 116 & $22 \%$ & 85 & $18 \%$ & 201 & $20 \%$ \\
\hline$>1.52$ & 410 & $78 \%$ & 390 & $82 \%$ & 800 & $80 \%$ \\
\hline Total Girls & 526 & $100 \%$ & 475 & $100 \%$ & 1001 & $100 \%$ \\
\hline
\end{tabular}

Table No.7 Prevelance of overweight and obesity in Girls according to BMI

\begin{tabular}{|l|c|c|c|c|c|c|}
\hline \multirow{2}{*}{$\begin{array}{l}\text { Category } \\
\left.\text { BMI (kg/m } \mathbf{m}^{\mathbf{2}}\right)\end{array}$} & \multicolumn{2}{|c|}{ Gujrati Girls } & \multicolumn{2}{c|}{ Non -Gujrati Girls } & \multicolumn{2}{c|}{ Total Girls } \\
\cline { 2 - 7 } & $(\mathbf{n})$ & $(\%)$ & $(\mathbf{n})$ & $(\%)$ & $(\mathbf{n})$ & $(\%)$ \\
\hline $\begin{array}{l}\text { Underweight } \\
\text { <18.5 }\end{array}$ & 24 & $5 \%$ & 19 & $4 \%$ & 43 & $4 \%$ \\
\hline $\begin{array}{l}\text { Normal weight } \\
\mathbf{1 8 . 5 - 2 4 . 9 9}\end{array}$ & 280 & $53 \%$ & 246 & $52 \%$ & 526 & $53 \%$ \\
\hline $\begin{array}{l}\text { Overweight Preobese } \\
\text { 25-29.99 }\end{array}$ & 212 & $40 \%$ & 196 & $41 \%$ & 408 & $41 \%$ \\
\hline $\begin{array}{l}\text { Obese Class 1 } \\
\text { 30-34.99 }\end{array}$ & 10 & $2 \%$ & 14 & $3 \%$ & 24 & $2 \%$ \\
\hline Total Girls & 526 & $100 \%$ & 475 & $100 \%$ & 1001 & $100 \%$ \\
\hline
\end{tabular}

Prevalence of Total, Gujarati and NonGujarati girls according to socioeconomic status:

In our study middle and upper status groups had highest prevalence of obesity and overweight. This is because of their high income, food habits and physical inactivity. In our study waist circumference in lower class was $29 \pm 3.17 \mathrm{~cm}$ as compared to waist circumference of $30 \pm 3.50 \mathrm{~cm}$ in the middle class. Body fat percent was also higher for the middle category $(26 \pm 8.12 \%)$ as compared to that in the lower class $(25 \pm 7.24 \%)$. Total body fat was higher for middle and upper class $(18 \pm 4.76 \mathrm{~kg}, 18 \pm 4.49 \mathrm{~kg})$ in comparison to that in lower class $(17 \pm 4.60 \mathrm{~kg})$.

Prevalence of Total, Gujarati and NonGujarati girls according to Inhabitance: 
We classified our subjects according to rural and urban category. Various statistics in past showed that urban population had greater prevalence of obesity and overweight. From our data, urbans are more affected, thus we report that prevalence has increased by two folds in rural population and by nine folds in urban population. The mean waist circumference in rural girls was less $(29 \pm 3.19 \mathrm{~cm})$ as compared to the mean waist circumference of the urban girls $(30 \pm 3.46 \mathrm{~cm})$ The body fat percent and total body fat of these girls were also less as compared to those in urban girls $(25 \pm 7.67 \% \mathrm{v} / \mathrm{s}$ $26 \pm 8.01 \%, 17 \pm 4.39 \mathrm{~kg}$ v/s $18 \pm 4.70 \mathrm{~kg}$ ).

\section{Prevalence of Total, Gujarati and Non- Gujarati girls according to diet:}

The girls of non vegetarian groups had higher weights and body mass index range as compared to the vegetarian category. This might be due to high fatty diets with less use of dietary fibers. The average weight, waist circumference, total body fat, lean body mass and skinfold thickness in vegetarian girls were low as compared to these in non vegetarian girls $(60 \pm 7.11 \mathrm{~kg} \mathrm{v} / \mathrm{s} 61 \pm 7.05 \mathrm{~kg}$, $29 \pm 3.50 \mathrm{~cm} \quad \mathrm{v} / \mathrm{s} \quad 30 \pm 3.56 \mathrm{~cm}, \quad 17 \pm 4.62 \mathrm{~kg} \quad \mathrm{v} / \mathrm{s}$ $18 \pm 4.75 \mathrm{~kg}, \quad 42 \pm 3.20 \mathrm{~kg} \quad \mathrm{v} / \mathrm{s} \quad 43 \pm 2.87 \mathrm{~kg}$, $56 \pm 8.53 \mathrm{~mm}$ v/s $57 \pm 8.61 \mathrm{~mm}$ ).

Prevalence of Total, Gujarati and NonGujarati girls according to weight and height:

Over weight and obese girls were present in the second and third category of weight range and normal weight girls mostly were of height more than $1.52 \mathrm{~m}$. The body fat percent, total body fat, lean body mass and skinfold thickness of girls with weight of $58 \pm 6.47 \mathrm{~kg}$ were low as compared to these in girls of weight of $65 \pm 5.28 \mathrm{~kg}$ $(23 \pm 5.17 \% \quad \mathrm{v} / \mathrm{s} \quad 38 \pm 3.82 \%, \quad 16 \pm 4.04 \mathrm{~kg} \quad \mathrm{v} / \mathrm{s}$ $22 \pm 3.52 \mathrm{~kg}, \quad 42 \pm 2.93 \mathrm{~kg} \quad \mathrm{v} / \mathrm{s} \quad 43 \pm 2.15 \mathrm{~kg}$, $54 \pm 7.69 \mathrm{~mm}$ v/s $63 \pm 6.99 \mathrm{~mm}$ ).

Prevalence of Total, Gujarati and NonGujarati girls according to body mass index:

In our study we also evaluated the average anthropometric characteristics of total girls according to BMI. The average weight, waist circumference, body fat percent, total body fat, lean body mass and skinfold thickness followed an increasing trend with increasing BMI. The increasing weights and waist circumference according to BMI were $48 \pm 3.15 \mathrm{~kg}, 56 \pm 4.66 \mathrm{~kg}$, $65 \pm 3.95 \mathrm{~kg}, 71 \pm 3.56 \mathrm{~kg} ; 26 \pm 1.15 \mathrm{~cm}, 27 \pm .22 \mathrm{~cm}$, $32 \pm 2.50 \mathrm{~cm}, \quad 37 \pm 2.22 \mathrm{~cm}$ respectively. The increasing body fat percent, total body fat, lean body mass and skinfold thickness according to BMI were $20 \pm 3.63 \%, 21 \pm 4.63 \%, 31 \pm 6.64 \%$, $41 \pm 6.04 \%$; $9 \pm 1.45 \mathrm{~kg}, \quad 15 \pm 3.82 \mathrm{~kg}, \quad 22 \pm 2.25 \mathrm{~kg}$, $27 \pm 1.75 \mathrm{~kg} ; 39 \pm 1.97 \mathrm{~kg}, 41 \pm 6.44 \mathrm{~kg}, 44 \pm 2.17 \mathrm{~kg}$, $44 \pm 2.00 \mathrm{~kg} ; \quad 46 \pm 7.03 \mathrm{~mm}, \quad 52 \pm 7.22 \mathrm{~mm}$, $61 \pm 6.52 \mathrm{~mm}, 71 \pm 4.27 \mathrm{~mm}$ respectively.

\section{Discussion}

Previous studies have shown that prevalence of obesity increases with advancing age. The 16-24 year age groups both males and females are substantially less at risk of becoming obese than older age groups and the increase of obesity for males in this age range has declined very slightly in recent years. Those aged between 25-34 years have the second lowest rates of obesity. Middle age people and those of retirement age are the most 'at risk' groups. More young males and females in 16-24 age groups have a desirable body mass index between 20 and $25 \mathrm{Kg} / \mathrm{m}^{2}$ than any other body mass index category. Males of this age are twice as likely to be underweight as they are to be obese ${ }^{[8]}$. British Heart Foundation (BHF) (2008) has proved in their article that overweight and obesity increases with age. In 2006 about 34 $\%$ of males and $32 \%$ females aged 16-24 year were overweight/obese compared to $80 \%$ of men aged 55-64 years and $73 \%$ of females aged 65$74^{[7]}$. The prevalence of central obesity also increases with age. About $10 \%$ males and $17 \%$ females aged 16-24 years had central obesity compared with $51 \%$ of males and $65 \%$ females aged $65-74^{[1]}$. The Scottish Executive (2005) Health survey proved that only $11 \%$ cases of obesity by waist hip ratio were reported for age 16-24 years while, $18 \%$ cases for 25-34 years and $54 \%$ cases for age 75 years and over. Joint health survey unit (2008) for England reported that according to BMI $12 \%$ cases of obesity were 


\section{JMSCR Vol||05||Issue||10||Page 29284-29294||October}

reported in age group 16-24 year,18\% cases in 2534 year and 27\% cases for age group 55-76 year were reported ${ }^{[4]}$. According to Waist Circumference prevalence in age group 16-24 year was $86 \%$ which increased to $94 \%$ in age group 25-34 and $103 \%$ for age group 65-74 for males and for females, 16-24 age group had prevalence of $77 \%$ which increased to $83 \%$ in $25-34$ age group while it was maximum of $92 \%$ for $65-74$ age group $^{[4]}$. Our analysis uncovers that weight increases with age. More percentage of overweight and obese girls was above 20 year age group. According to Parizkova J et al (2007)
[REF] India being a country of diverse population, it has regions still struggling with burden of malnutrition but at same time there are rapidly emerging populations subgroups which are falling into trap of affluence related problems. The socio economic development has created changes in dietary intake, food consumption patterns and physical activity levels. They all have contributed to problem of increasing overweight to obesity. India is passing through transitional phase of socio economic development which has potential of altering the nutritional status of its population ${ }^{[4]}$.
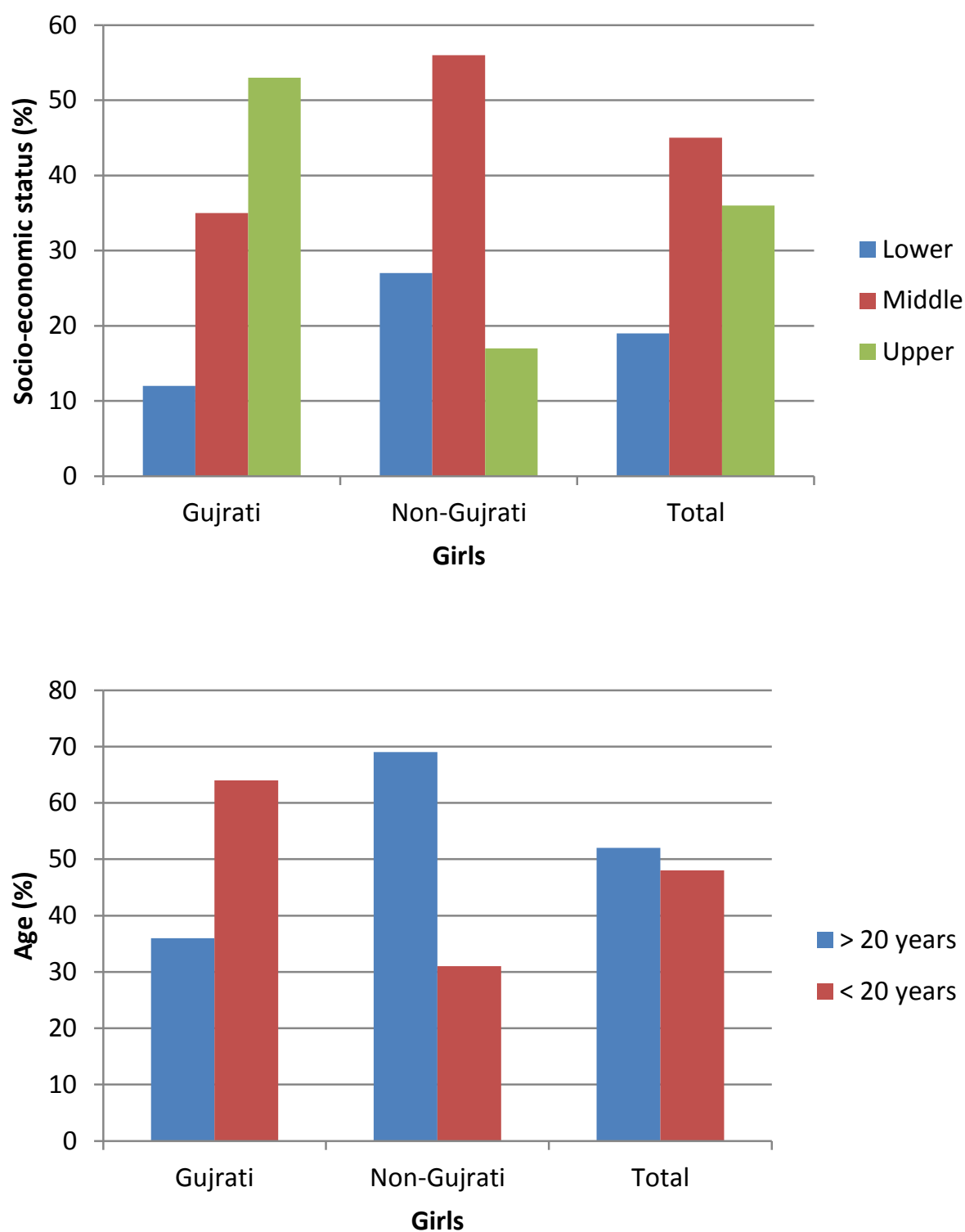


\section{JMSCR Vol||05||Issue||10||Page 29284-29294||October}
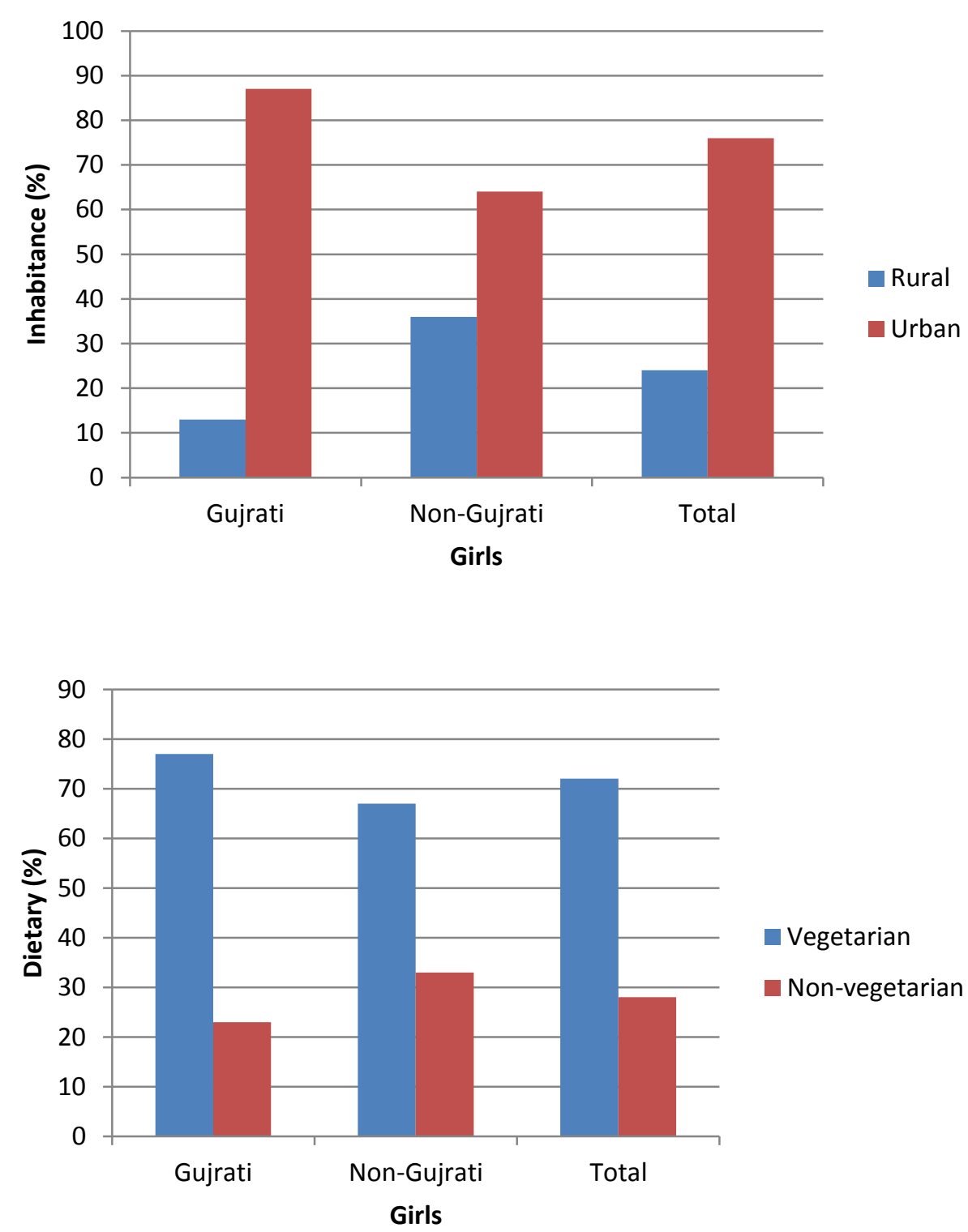

Graph.1: Distribution of Girls According to Age, Inhabitance, Socioeconomic Status and Dietary Habits.

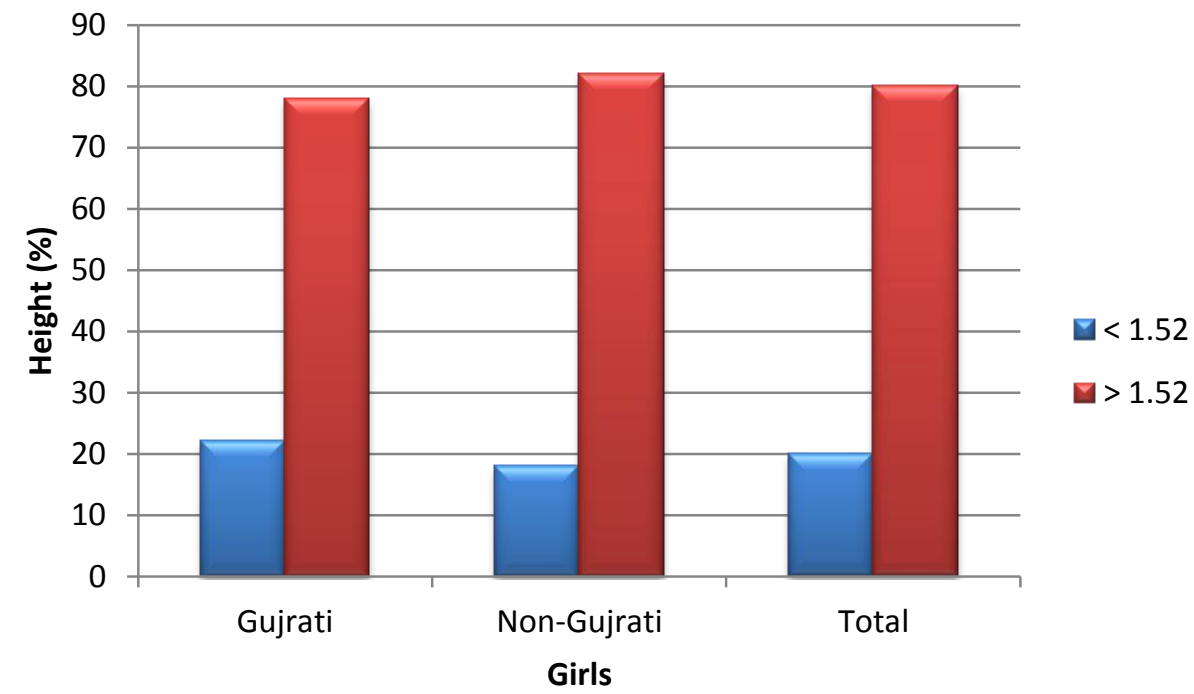



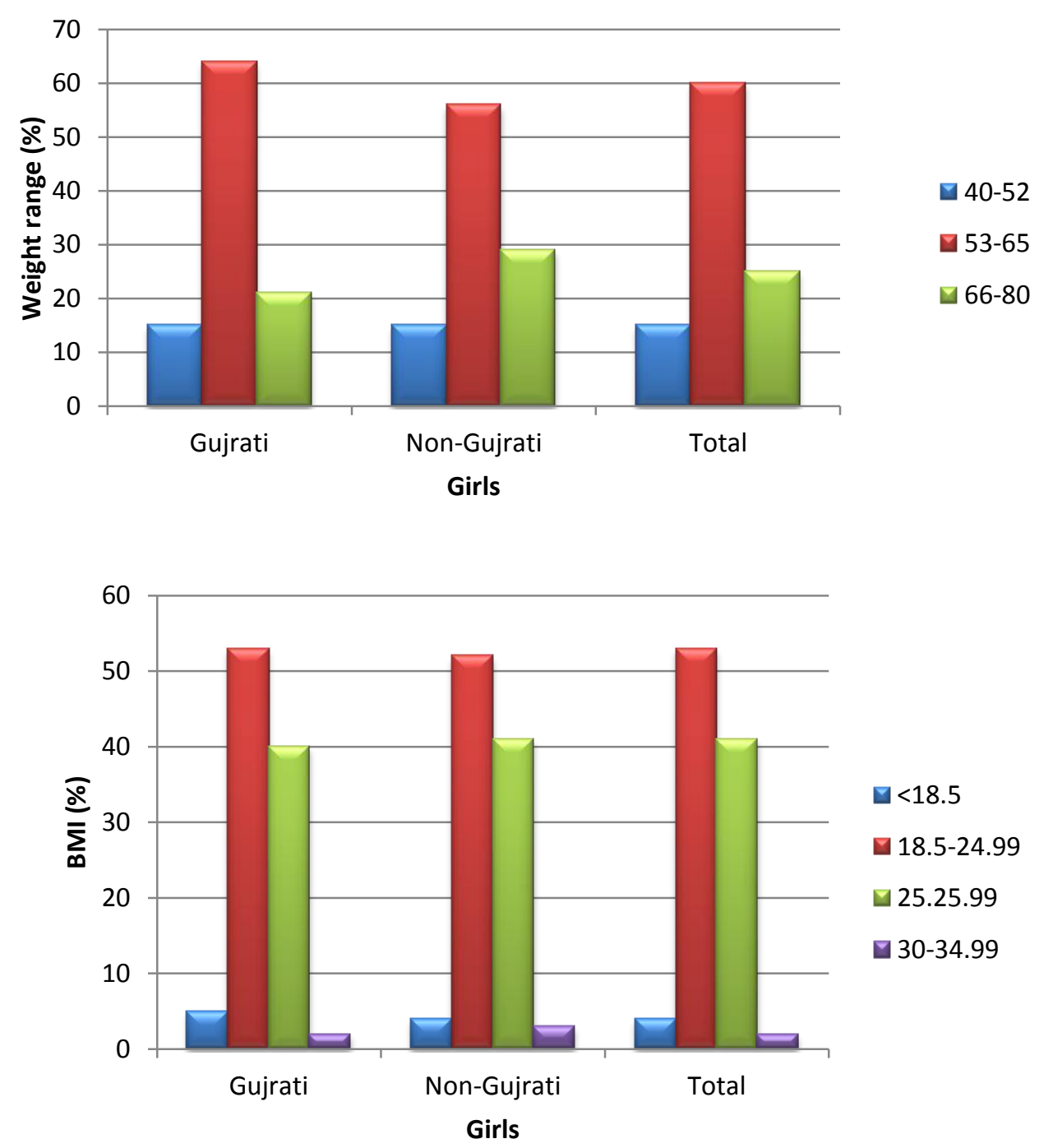

Graph.2: Distribution of Girls According to Weight Range, Height, BMI

Socioeconomic status, which includes educational status, income per capita and profession, has a very crucial impact on prevalence of obesity and overweight, as evident in this study. In our study middle and upper status groups had highest prevalence of obesity and overweight. This is because of their high income, food habits and physical inactivity. Overweight and obesity are more prevalent among those with higher levels of education and people with high income, but is inversely related to socioeconomic status at given ages $^{[7]}$. Obesity develops in a socio cultural environment, characterized by mechanization, sedentary life style and ready access to abundant food, environmental and behavioural changes brought about by economic development; modernization etc. has been linked to the rise of global obesity (Talmund PJ et al) $(2004)^{[5]}$. Among poorer nations adoption of industrialized food and food preferences, together with drastically decreased physical activity are the basic ingredients for accelerating obesity. Within developing countries, shifts to urbanization, non manual labour, high calorie food, sedentary life style are contributing to this growing problem, often in conjunction with undernourished segments of the population. Inhabitance difference in prevalence of obesity within India also provides information regarding risk factors that need prevention. Various statistics in past showed that urban population had greater prevalence of obesity and overweight. ${ }^{[3]}$ reported that urban prevalence of obesity was three times that of rural leading to glucose intolerance, diabetes mellitus and hyper 
insulinemia. The increasing trend could be due to improper diet, may be traditionally rich food lacking in antioxidants and stress. From our data, urbans are more affected but over the period of time, rise in rural obesity subjects was also seen. The study showed that urban sub group had greater hypertension, sedentary life styles and total cholesterol levels. Decadal variation shows that obesity prevalence in urban population was 3.56 in 1960's, 3.89 in 1970's and 10.56 in 1990 's. In the rural population the prevalence increased from $2.72 \%$ (70's) and $2.1 \%$ (80's) to $4.57 \%$ (90's). Thus they reported that prevalence has increased by two folds in rural population and by nine folds in urban population.. A relative lack of fiber in the diet of western world has been linked with increasing risk of several diseases like cardiovascular diseases, coronary artery diseases, cerebrovascular diseases, diabetes mellitus all of which are risk factors of obesity. Consumption of number of grains and grain extract has been reported to control and improve glucose tolerance and reduce insulin resistance. These conditions are associated with obesity and may be preliminary steps in progression of many chronic side effect diseases of obesity ${ }^{[1]}$. For year's dietary guidelines for treatment of overweight and obesity have advised a low fat, low calorie diet. We categorized our girls according to their eating habits as vegetarian and non vegetarian groups. The girls of non vegetarian groups had higher weights and body mass index range as compared to the vegetarian category. This might be due to high fatty diets with less use of dietary fibers. Overweight and obesity are both labels for ranges of weight that are greater than what is generally considered healthy for a given height. The initial step in evaluation of obesity is calculation of body mass index. It correlates significantly with body fat, morbidity, mortality, calculated easily and quickly and even recommendations for treatment of obesity are based on body mass index. According to them, a person with a body mass index of $23 \mathrm{~kg} / \mathrm{m}^{2}$ will now be considered as overweight and below that as one with normal
BMI - unlike the cut off limit of $25 \mathrm{~kg} / \mathrm{m} 2$ earlier. Those with BMI of $25 \mathrm{~kg} / \mathrm{m}^{2}$ will be clinically termed obese as opposed to $30 \mathrm{~kg} / \mathrm{m}^{2}$ at the international level, and those with BMI of $32.5 \mathrm{~kg} / \mathrm{m}^{2}$ will require bariatric surgery to estimate excess flab ${ }^{[4]}$. A BMI of $25 \mathrm{~kg} / \mathrm{m}^{2}$ is generally accepted threshold for identifying a patient at high risk for obesity related diseases (38). BMI $<18.5 \mathrm{~kg} / \mathrm{m}^{2}$ is considered underweight, In our analysis $41 \%$ girls were overweight and $53 \%$ belonged to normal weight category according to BMI. In our study we also evaluated the average anthropometric characteristics of total girls according to BMI. The average weight, waist circumference, body fat percent, total body fat, lean body mass and skin fold thickness followed an increasing trend with increasing BMI.

\section{Summary}

\section{Epidemiological Study}

The 1001 girls residing in different hostels from different colleges were selected for the study. Two groups were made and the total girls were categorized into Gujarati and Non Gujarati groups respectively. They were further classified according to categories like age, inhabitance, socioeconomic status, diet, weight, height, body mass index,

1) The total girls who belonged to the age group of less than twenty years were $48 \%$ and more than twenty years were $52 \%$. Sixty four percent Gujarati girls were present in age $<20$ years, while only $36 \%$ were above 20 years. Thirty one percent Non Guajarati's were less than 20 years while $69 \%$ were more than 20 years.

2) The total girls who belonged to rural inhabitance were $24 \%$ and to urban inhabitance were $76 \%$. Thirteen percent Gujarati girls were rural inhabitants, and $87 \%$ belonged to urban category. Thirty six percent Non Guajarati's were rural inhabitants, while $64 \%$ belonged to urban category. 
3) The total girls who belonged to lower, middle and upper socioeconomic categories were $19 \%, 45 \%$, and $36 \%$ respectively. Twelve percent Gujarati girls were part of lower category, 35\% were belonging to middle category and 53\% were having upper socio economic status. Twenty seven percent Non Guajarati's were part of lower category, $56 \%$ belonged to middle category and only $17 \%$ had upper socio economic status.

4) The total percentage of girls who were strictly vegetarians was $72 \%$, and those belonging to non-vegetarian category were $28 \%$ only. Seventy seven percent Guajarati's were vegetarians while $23 \%$ were non-vegetarians. Sixty seven percent Non Guajarati's were vegetarians and 33\% were non vegetarians.

5) The total percentage of girls belonging to weight range 40-52 $\mathrm{kg}$ (category 1) were $15 \%$, those in weight range $53-65 \mathrm{~kg}$ (category 2) were $60 \%$ while those in weight range 66-80 kg (category 3) were $25 \%$ only. Fifteen percent Guajarati's belonged to first category, $64 \%$ belonged to second category and $21 \%$ were in the third category. Similarly $15 \%$ Non Guajarati's belonged to first category, $56 \%$ were in second category and $29 \%$ were part of third category.

6) The total girls with height $<1.52 \mathrm{~m}$ were $20 \%$ and with height $>1.52 \mathrm{~m}$ were $80 \%$. Twenty two percent Gujarati girls were of height $<1.52 \mathrm{~m}$ and $78 \%$ were of height $>1.52 \mathrm{~m}$. Eighteen percent Non Gujarati girls belonged to category of height $<1.52 \mathrm{~m}$ while $82 \%$ belonged to category of height $>1.52 \mathrm{~m}$.

7) The total girls who were underweight according to body mass index were only 4\%. Normal weight category had maximum $53 \%$ girls, $41 \%$ belonged to overweight or pre obese category and only $2 \%$ belonged to obese class 1 category of body mass index. Five percent Gujarati girls were underweight according to body mass index, $53 \%$ were normal weight, $40 \%$ were overweight and $2 \%$ percent were obese. Four percent of Non Gujaratis were underweight according to body mass index, $52 \%$ were normal weight, $41 \%$ were overweight and $3 \%$ were belonging to obese class 1 category.

\section{Conclusion}

Majority of our subjects were more than 20 years of age (52\%). Most of them (76\%) belonged to urban areas and $45 \%$ had middle socio economic status. Mainly the girls were strictly vegetarians (72\%). Sixty percent total girls had a weight range of $53-65 \mathrm{~kg}$. Only $20 \%$ had height less than $1.52 \mathrm{~m}$. Forty percent were in overweight category according to body mass index with BMI range of $25-29.9 \mathrm{Kg} / \mathrm{m}^{2}$. At the beginning of the third millennium, obesity became the most frequent global metabolic disease ${ }^{[6]}$. Increasing prevalence has been shown not only in the industrially developed countries, but also in the developing countries. This concerns all age categories because of the investigation of dietary behaviour and dietary lifestyles specifically in girls ${ }^{[9]}$ and the prevalence of obesity varies remarkably across countries with different socioeconomic development levels.

\section{References}

1. Fukushige $\mathrm{T}$, Yoshinaga M, Shimago A, Nishi J, Kono Y, Nomura Y, Miyata K, Imamura M, Shibata T, Nagashima M, Niimura I (2002): Effect of age on overweight.Am J Cardiol; 89: 395398.among medical

2. George Bertsias, Ioannis Mammas, ManolisLinardakis, Anthony Kafatos (2003): Overweight and obesity in relation to cardiovascular disease risk factors students in Greece. BMC 3:3.

3. Himeno E, Nishino K, Nakashima $\mathrm{Y}$, Kuroiwa A, Ikeda M (1996): Weight 
reduction in obese subjects. Am Heart J; 131: 313-319.

4. Ian Janssen, Steven B, David B, Donald P, Robert Ross (2002): Body mass index and waist circumference independently contribute to the prediction of nonabdominal, abdominal, and visceral fat. American Journal of Clinical Nutrition; 75: 683-688.

5. Kuczmarski RJ, Flegal KM, Campbell SM, Johnson CL (1994): Increasing prevalence of overweight among US adults: The National Health and Nutrition Examination Surveys, 1960 to 1991. JAMA; 272: 205-211.

6. Must A, Jacques PF, Dallal GE, Bajema CJ, Dietz WH (1992): Mortality of overweight adolescents: $N$ Engl J Med; 327: 1350-1355

7. Nakajima T, Fujioka S, Tokunaga K, Matsuzawa Y, Tarui S (1989): Intraabdominal fat accumulation in obesity. Am J Cardiol; 64: 369-373.

8. Peiris AN, Thakur RK, Sothmann MS, Gustafson AB, Hennes MI, Wilson CR, Kissebah AH. Relation of regional fat distribution and obesity. South Med J 1991; 84: 961-5.

9. Streicher R, KotzkaJ,Muller-Wieland D, Siemeister G, Munck M, Avci H, Krane W [1996] :Insulin like growth factor1,Journls of biological chemistry 271:7128-7133. 